\title{
Changing Focus: Exploring Images of Women and Empowerment in Egypt
}

\author{
Kristina Hallez
}

Abstract In moving away from prescriptive one-way communications exercises, participatory development communications use better strategies to engage communities and capture nuance. This article examines a communications case study in Egypt: a photography competition aimed at understanding how local photographers depict women and empowerment in their images. Opportunities for discussion and selfreflection provide cultural producers the space to delve into how they see women and how they then choose to represent them. This type of communications initiative actively courts a richer understanding of empowerment, leaving room for the complexities this might entail.

\section{Changing Focus}

How do cultural producers view women's roles and what do they intend to project when they share their creations with the public? The Changing Focus Photography Competition, a communications project of the Middle East Hub of the Pathways of Women's Empowerment Research Programme Consortium, addresses these very questions. As a collaborative network of research centres in the global South, Pathways researchers work together on specific themes to investigate notions of women's empowerment. In addition to innovative research, Pathways focused heavily on utilising alternative and participatory communications strategies. Changing Focus invited Egyptian photographers to engage with each other and share their depictions of how women navigate the world around themselves. How do Egyptian photographers conceptualise women's empowerment? How do they connect their own ideas about empowerment with their images? John Tagg suggests that a photograph provides a 'politically mobilised rhetoric of truth' through which photographers can frame social situations in a variety of ways (Knowles and Sweetman 2004). This project sought to understand how photographers frame and communicate their ideas about women's agency through their art and representations.

\section{Structure of Changing Focus}

While certain stereotypes of Middle Eastern women remain embedded in Western views (Nusair 2009), the participation of women in the ongoing Egyptian Revolution provides numerous narratives that subvert such stereotypes. This is not to say that it was solely a revolutionary spark that fuelled different representations. Prior to the uprising, regional women's organisations experimented with different media channels to disseminate research and publicise their messages as a move away from these stale representations (Skalli 2006 in Nusair 2009). Skalli has discussed the need for women to be more creative and strategic as they craft their representations. Changing Focus was envisioned as a space to do just that - to create and reflect upon their representations of women through photography. As a communications medium, photographs contain their own texture, providing detail and capturing dimensions that may be hard to describe solely through the written or spoken word (Rose 2007).

In early 2010, photographers were invited to submit a brief application (contact details and information about how long they have been taking photos as well as their engagement with any other arts activities) and three photographs accompanied by a short description/discussion (300-500 words) of them. 


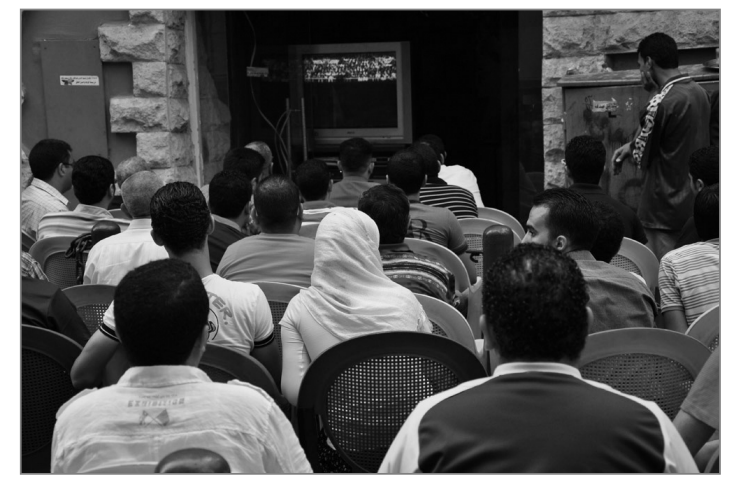

Photo by Ahmed Rady, Changing Focus participant

The application process was open to Egyptian nationals and foreigners who have lived in Egypt and are engaged with the context. The application and posters were written and distributed in Arabic and English and submissions in either language were accepted. We acknowledge that the competition framework comes with certain limitations. The expectation that applicants provide their own photography equipment created socioeconomic barriers to entry. Equipment is expensive (albeit to varying degrees and there were no requirements as to what kind of camera participants should use) and with this expectation, we had to acknowledge that this process would be exclusionary for those who could not afford such costs. This issue marks a tension in the creation of cultural material in general. She who has the financial capacity then has a greater ability to create and distribute artistic goods, thus a further reach and further power to push her own conceptions and depictions.

A panel of three judges working within Pathways assessed applicants using the following rubric:

- Artistic merit - Aesthetic quality of the photographs (scale of 1-10);

- Conceptualisation of gender empowerment How well the applicant was able to portray or convey their interpretation of women's empowerment in their photos (scale of 1-10);

- Understanding gender empowerment - How well the applicant was able to discuss the meaning and intent behind their photos in their application (scale of 1-15).

Selected applicants were invited to attend a oneday workshop with an artist facilitator to discuss gender and representations of women as well as their photos and what they conveyed. We were fortunate to secure the help of Huda Lutfi, who is both a cultural historian and artist (Mehrez 2008). She continually visits themes of gender, history and representation through her artwork, exploring how masculinity and femininity are constructed in the Egyptian context. Following the workshop, the photographers then submitted new photos and a brief description of a dream photography project involving women. A winner was chosen based on the same rubric above and given prize money that could be used toward their suggested photography project.

\section{Methodological underpinnings}

Changing Focus is concerned with the space to create and discuss representations of women and empowerment. It is foremost a participatory communications initiative, using a feminist lens to embrace intersections of research, representation and art. Increased women's participation and agency will not come through changing laws and policies alone. The transformative process should also address societal representations of women, encouraging and publicising images that delve into the everyday realities of women.

\section{Development communications}

Communications work has become as an integral and participatory part of the development process, marking a shift that has occurred over the last few decades. Development communications used to primarily encompass the transmission of information, 'not meant to communicate, just to inform, conform and deform', in efforts to achieve economic or political gain and prop up local elites, governments and multinational corporations (Gumucio-Dagron 2008: 70). Participatory approaches were taken up to foster multidirectional communication, to encourage a collective goal rather than a predetermined endpoint and results. Communications work can serve as a reflection from the community back on the processes being carried out in the community, an opportunity for skills-training and capacitybuilding, and even as a therapeutic and emotive outlet. A primary concern is to understand the motives for participation and why people do or do not engage in development projects. Communications initiatives can be mechanisms through which beneficiaries and participants share their views and discuss successes, shortcomings and general reactions to development projects. Changing Focus embraces 

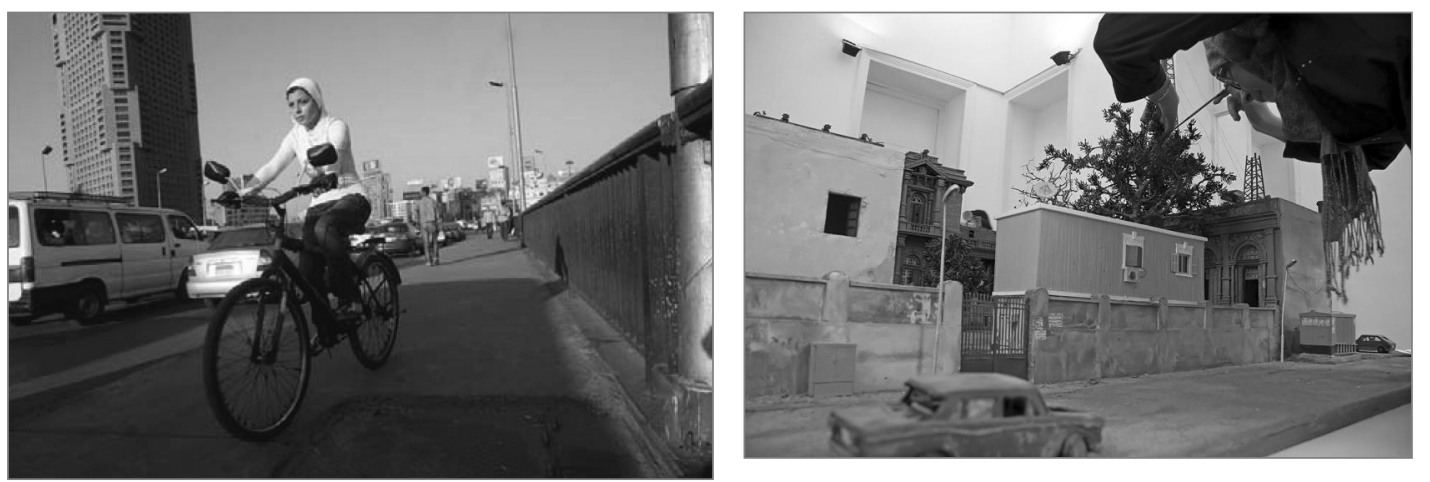

Two photos by Heba Khalifa, Changing Focus participant

this framework, looking to participating photographers as researchers working to conceptualise gender empowerment.

\section{Communication and women's empowerment}

The Changing Focus Photography Competition project is a communications venture that aims to share representations of women and, in doing so, works to spread and support Pathways' messages that emphasise the different experiences of women. Jan Servaes describes a development paradigm ('Multiplicity in One World') that acknowledges there is no universal path to development, but rather pathways that vary from one community to the next as 'integral, multidimensional, and dialectic process' (1996: 83). This paradigm seems apt in conceptualising what constitutes empowerment in women's lives. There is no singular universal way to foster empowering circumstances. Linking representation, feminism and the field of communication, Keya Ganguly stresses that feminist critique should acknowledge 'the fractured representation of fractured identities' (1992: 61). Communications initiatives should strive to bring varying realities to the fore. She argues that the diversity within feminist practices lends itself to a multitude of approaches and feminist research must continually involve self-reflection. Changing Focus was intended to provide time, space and prompts for this kind of deconstruction. The photographers brought forward their images, wrote about them, and discussed them. The resulting images are their conceptions of empowerment, with all the complexities and nuances that they imbued.

It was also crucial that the project address local stakeholders, here photographers, who have their own insights and ideas about how they see society functioning around them. The participatory approach suggests that, immediate context, a perspective quite different from the abstract concepts, hypothetical scenarios and standardized strategies which occupy the minds and consume the budgets of "experts"' (Arnst 1996: 112).

\section{Visual methodology, representation and art} Caroline Knowles and Paul Sweetman describe how visual techniques and methods are particularly useful in 'Allowing us to understand how the smallest units of social analysis - people, lives, the minutiae of material culture - operate in relation to broader social landscapes and bigger processes, visual strategies offer a way into understanding how the personal is social and the social personal' (2004: 8). Images have the ability to bring us more information and a potentially larger sense of social and spatial relationships on many different levels. As digital photographic tools have become more accessible, photos can be an excellent communications tool. The 1920s saw a rise in the depictions of women as demonstrators and activists, showing the contribution of women to the creation of the nation (Baron 2005). Al-Ali comments on how different aspects of nationalism encompass different depictions of women, among them the portrayal of women as citizens with obligations and entitlements from the State and of women as the guardians or symbols of cultural norms and values (2000).

Knowles and Sweetman discuss the limitations and benefits of visual methodologies, pointing out concerns around misrepresentation and manipulation of images to display certain 'Participants are more capable because it is their 

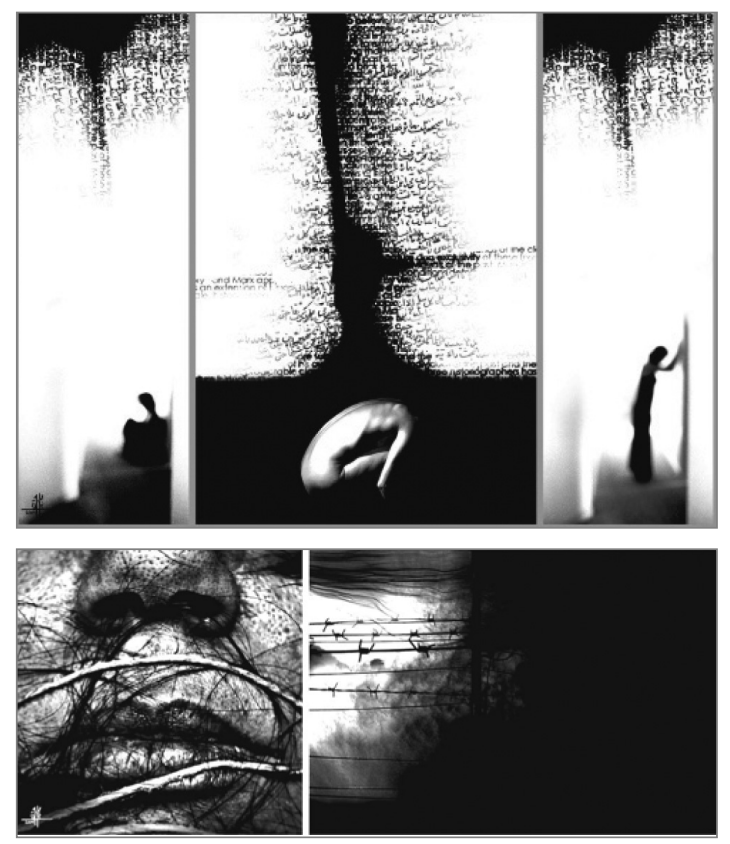

messages. Changing Focus acknowledges these paradigms and thus asked participant photographers to discuss their images and what they wanted to convey. This process does not rule out other interpretations but allows the photographers to explain their representations of women so audiences have access to their point of view.

There is a space for understanding how artistic communications projects function in the communities that host them. In the mid 2000s, compared to research available on more formal political spheres in the Middle East, there was a tangible dearth of information about alternative media in social activism (Williams 2004). Since then, increased access to/usage and the Egyptian Uprising has generated massive interest in the use of activist social media (Eltantawy and Weist 2011). The Revolution has been accompanied by a boom in public artistic production (Lindsey 2012; Pahwa and Winegar 2012). Once-rare political graffiti has become commonplace throughout Cairo and other Egyptian cities. Artists, playwrights, activists and enthusiastic citizens have created multiple events like AlFann Midan [Art is a Square] to commemorate and reflect upon change in Egypt. Some groups, like the media collective Mosireen [Those who Insist] and Askar Kazeboon [Military Liars], use public film footage screenings to spark dialogue with fellow citizens about social justice and the failings of the government and military.

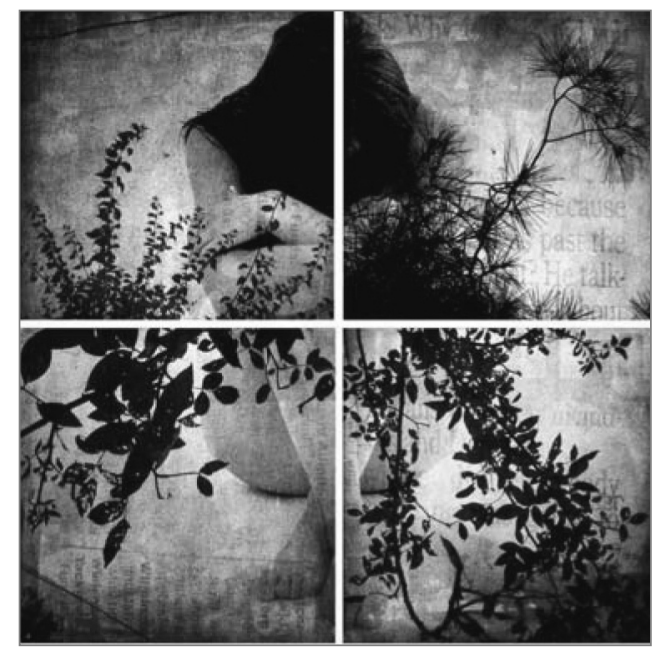

Three photos by Marwa Adel, Changing Focus participant

Changing Focus allows us to see the images of Egyptian photographers just before the Revolution began, an insight into their representations of women before the current transitional period.

\section{The photographers}

Photo journalist Heba Khalifa captured a woman riding a bicycle, generally considered a mode of transportation only suitable for men. Khalifa discusses the transformative power of this woman on her bike actively rejecting accepted norms about how women are supposed to behave. Another photo submitted by Khalifa depicts a female artist working on a model replicating a neighbourhood in downtown Cairo. The replica is part of a collaborative art project entitled 'Model Citizens' in which neighbourhood members were interviewed before and after the model construction and asked what they would like to change about their neighbourhood. Any changes they suggested were then incorporated into the model, allowing residents to visualise their suggestions (http://wouterelke.nl/cairo/ accessed 19 June 2012). Khalifa describes the powerful visual contrast between the tiny city and the artist looming large like a giant. She notes the artist's role as a creator, in total control of the reality beneath her. Khalifa goes on to discuss how the women in her photos manage to escape or rise above the crowds and noise of the city and its pressures. She sees them gaining strength and energy from these personal activities. 


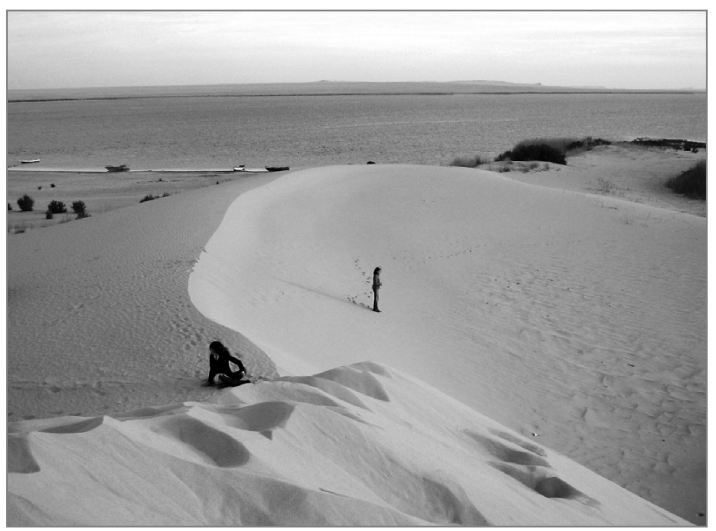

Photo by Karina Shalaby, Changing Focus participant

Photographer Ahmed Rady also turns an eye to the ways women take up transgressive opportunities. One of his images, entitled 'Right to Express Yourself' depicts a lone woman watching a football match, surrounded by men. Rady explains that 'Socially constructed roles too often frustrate the potential of girls and women... Empowerment and change in women's lives happen when they develop and cultivate their own interests and passions regardless of social conventions'. He sees this woman finding a way to enter a typically maledominated space and enjoy the match with everyone else.

Marwa Adel focused her images more directly on the female body, playing with high contrast and posed forms. Her photos, which have been digitally manipulated, bring forward symbols of silencing and constrained turmoil. In her application, she noted that her submission reflected three stages in her own life: 'Feeling a prisoner of traditions', 'confrontation and resistance', and 'serenity' after having 'decided to be who I am without concern for the restrictions set by others'. Her visual reflection on her own journey allows the viewer to see the photographer-researcher symbolically turning the lens on herself. Adel uses her photography to reflect on what empowerment means in her life and as a mode of explanation to the world.

Marwa Abdel Fattah's image of a woman whose face is obscured by a fingerprint generated quite a bit of discussion at the workshop. Abdel Fattah described the photo as a reflection of how often female identity is erased because life centres around men. In this context, she believes women

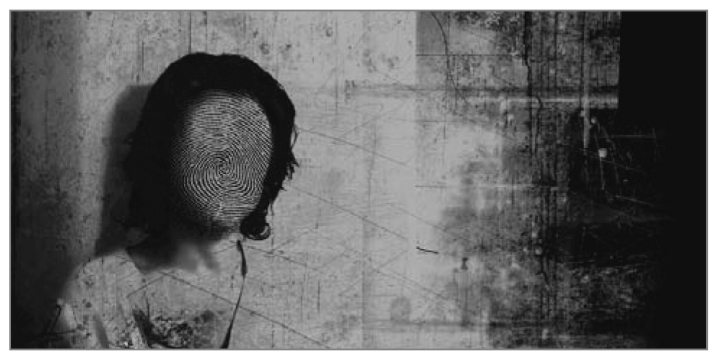

Photo by Marwa Abdel Fattah, Changing Focus participant

often forget that they too have a right to their own existence. Some workshop participants felt that the fingerprint signified a unique identity and was a symbol of civic power (a signature). Others felt the opposite, citing that the removal of the woman's facial features and replacement with an unidentified swirl implied confusion and female conformity.

Photographer Karina Shalaby focused on the relationship between women and the natural world as a source of empowerment. She described the outdoors as a freeing space, where women can escape male pressure and exist as 'active agents... in a dynamic connection with the forces of nature'.

\section{Re-focus}

The photographer responses to the Changing Focus process suggest that a participatory communications approach can provide a lively forum for discussion and creation. The opportunity for artists to share their thoughts through image, text and word brought forth a variety of images and interpretations about gender and empowerment. As cultural producers, these photographers occupy a creative and transformative space. Their different narratives about women's lives bring us deeper into Ganguly's 'fractured representation of fractured identities' (1992). H. Leslie Steeves and Luz Estella Porras synthesise a particularly helpful way in which to understand the body and how it shapes our identities and constructs the way we experience and interact with the world around us: 'The body is not only a private realm, but a site where multiple social oppressions and liberating experiences converge' (2009: 155). Using bodily images as an entry point, these photographers bring us into conversations about what real women are thinking, feeling, and experiencing. 


\section{References}

Al-Ali, Nadje (2000) Secularism, Gender and the State in the Middle East: The Egyptian Women's Movement, Cambridge: Cambridge University Press

Arnst, Randall (1996) 'Participation Approaches to the Research Process', in Jan Servaes, Shirley White and T.L. Jacobson (eds), Participatory Communication for Social Change, New Delhi: Sage

Baron, Beth (2005) Egypt as a Woman: Nationalism, Gender and Politics, Berkeley: University of California Press

Eltantawy, Nahed, and Weist, Julie B. (2011) 'Social Media in the Egyptian Revolution: Reconsidering Resource Mobilization Theory', International Journal of Communication 5: 1207-24

Ganguly, Keya (1992) 'Accounting for Others: Feminism and Representation', in Keya Ganguly and Lana F. Rakow's (eds), Women Making Meaning: New Feminist Directions in Communications, London: Routledge

Gumucio-Dagron, Alfonso (2008) 'Vertical Minds Versus Horizontal Cultures: An Overview of Participatory Process and Experiences', in Jan Servaes (ed.), Communication for Development and Social Change, New Delhi: Sage

Knowles, Caroline and Sweetman, Paul (2004) 'Introduction', Picturing the Social Landscape: Visual Methods and the Sociological Imagination, London: Routledge

Lindsey, Ursula (2012) 'Art in Egypt's Revolutionary Square', Middle East Research and Information Project, Interventions, www.merip.org/mero/interventions/art-egyptsrevolutionary-square (accessed 19 June 2012)
Mehrez, Samia (2008) Egypt's Culture Wars Politics and Practice, Cairo: American University in Cairo Press

Nusair, Isis (2009) 'Gender Mainstreaming and Feminist Organizing in the Middle East and North Africa', in Nadje Al-Ali and Nicola Pratt (eds), Women and War in the Middle East, London: Zed Books

Pahwa, Sonali and Winegar, Jessica (2012) 'Culture, State and Revolution', Middle East Research and Information Project 42.263

Rose, Gillian (2007) Visual Methodologies: An Introduction to the Interpretation of Visual Materials, London: Sage

Servaes, Jan (1996) 'Participatory Communication Research with New Social Movements: A Realistic Utopia', in Jan Servaes, T.L. Jacobson and Shirley White (eds), Participatory Communication for Social Change, New Delhi: Sage

Skalli, Loubna H. (2006) 'Communicating Gender in the Public Sphere: Women and Information Technologies in the MENA Region', Journal of Middle East Women's Studies 2.2: 35-59

Steeves, H. Leslie and Porras, Luz Estella (2009) 'Feminism in a Post-Development Age', in Thomas McPhail (ed.), Development Communication - Reframing the Role of the Media, Chichester: Wiley-Blackwell

Williams, Karin Gwinn (2004) 'Communication and Transition in the Middle East', in Alfonso Gumucio-Dagron and Tufte Thomas (eds), Communication for Social Change Anthology: Historical and Contemporary Readings, South Orange: Communication for Social Change Consortium 